from one to the other, regardless of objectives. All three form the functioning nexus of the science-government relationship. There is nothing mythical about this. The world works through decisions and this description simply reflects the way in which people have to operate in order to get anything done at all. This is, as Snow said, "how the world ticks".

As to the three principal cases in Herken's analysis, their most interesting aspects are clearly the awkward attempts of Leo Szilard, Albert Einstein, Niels Bohr, J. Robert Oppenheimer, Edward Teller and many others to affect the policy, politics and political decisions of the US government. There are many wonderful synopses of the scientists' feeling that "we could not assume responsibility", that they were "swimming in syrup", that they were "all green" and that "we did not even speak the same language". And in many ways, the cases chosen are superb examples of Snow's closed political system. But one cannot escape the sense that these cases are but synopses of important events, each of which already has a good number of more detailed and fascinating books to its credit. Nor can one escape the sense that little is made of the great potential to analyse the book's chosen cases in Snow's full framework. As Snow made clear, a nation with a concentration of personal power on matters of science has on its hands essentially a dangerous democracy. But although many of Herken's cases feature personalities with exactly such power, he ventures no such judgements about political validity.

Much has been written in recent years on the role of chief science advisers, on the proper structure of science advice and on the dissemination of balanced scientific information to all levels of government. In practice, the US president's power is countered by a system of checks and balances between Congress and the public. And in practice, there are hundreds of science-based departments and agencies in the United States, each of which filters and jockeys its views into the 'corridors of power' using mechanisms that are clearly 'Snovian'. And in practice, a great many scientists, science-policy analysts and policy advisers combine to give summary advice to the highest levels of government. Unfortunately, though promising, Cardinal Choices provides one more trip into Promethean territory, and not an illumination of science advice in modern times. $\square$

John de la Mothe is in the Public Policy and Management Group, Faculty of Administration, University of Ottawa, Ottawa, Canada K1N 6N5 and at the J. F. Kennedy School of Government, Harvard University, Cambridge, Massachusetts 02138, USA.

NATURE · VOL $359 \cdot 3$ SEPTEMBER 1992

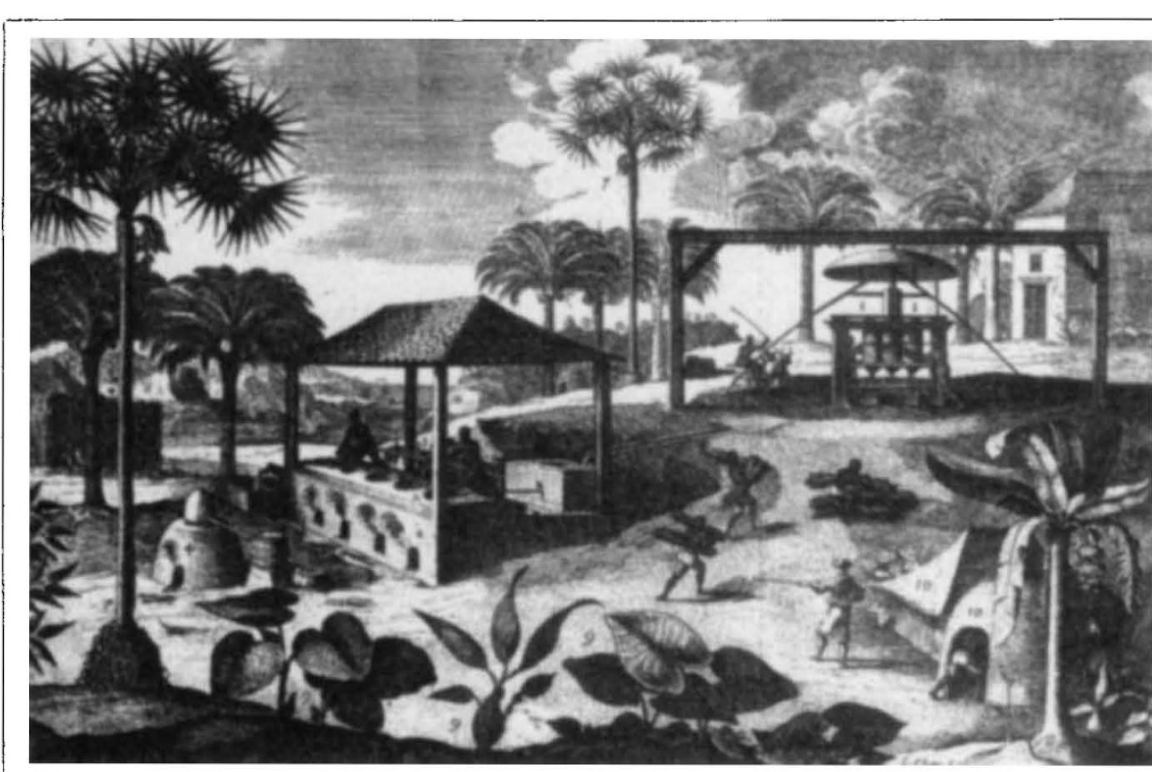

A sugar mill, from J. B. Dutertre's Histolre générale des Antilles (1667). The picture is taken from Coloniallsm and Science by James E. Mcclellan III, which explores the relationshlp between science and colonialism in the eighteenth-century French West Indian colony of Saint Domingue (modern-day Haiti). Published by The Johns Hopkins University Press, price \$52, £37.50.

\title{
Sex, soma and senescence
}

\section{Darryl T. Gwynne}

The Evolution of Life Histories. By Stephen C. Stearns. Oxford University Press: 1992. Pp. 249. £16.95, \$29.95.

I HAVE often thought that fields dealing with trait adaptation, such as physiological or behavioural ecology, could have more informative titles. 'Ecology' tends to direct one's thinking towards influences from the external (physical and biotic) environment. However, as we learn from this book, the most important aspect of the environment of any of an organism's traits are its other traits. Stearns studies evolution by examining adaptive compromises between individual life-history traits such as age, size and life span. In his view, this 'one trait at a time' analysis is partly a response to the failure of the approach in which all life-history traits are considered together (such as $r$ and $K$ selection theory).

Although aimed at advanced students, this work will be read much more widely, because the basics of life-history theory pervade all pure and applied branches of ecology, ethology and evolution. Stearns sets us on the right track for understanding interactions between traits, just as G. C. Williams did to trait selection in general with his Adaptation and Natural Selection (1966). But Stearns' review is not just a microevolutionary one. He weaves in an important chapter on phylogenetics and compara- tive analysis, illustrating how past evolution can constrain continuing trait interaction.

It is not only the theme that makes the book an excellent read. I enjoyed the questions and comments designed to stimulate research and the occasional tales of, for example, food-unlimited kestrels and 200-year-old molluscs. The text flows well from start to finish because of clear summaries in, and connections between, the chapters. This is especially true of the first section on the fundamentals, which contains a lucid discussion of concepts such as natural selection, adaptation and fitness.

The reader is then introduced to trait evolution by learning how demography allows calculation of the intensity of natural selection and how the use of quantitative genetics can determine the response to this selection. Here, Stearns places genetics in nature by showing how genetic variation is expressed in different environments (using reaction norms to analyse plasticity). Compared with other (for example, metric) traits, life-history (fitness) traits are predicted to have reduced genetic variation. In reviewing the evidence, Stearns concludes that, although these traits do indeed have lower heritabilities, they can evolve because there is sufficient underlying genetic variation. But this conclusion is reached without any reference to comparative data on genetic variation. Heritability and genetic variation are not the same and, as it now turns out, lower heritabilities of fitness traits are 